\title{
Who's Superconnected and Who's Not? Investment in the UK's Information and Communication Technologies (ICT) Infrastructure
}

\author{
Edward Oughton ${ }^{1 *}$, Peter Tyler ${ }^{2}$ and David Alderson ${ }^{3}$
}

\begin{abstract}
The Information and Communication Technologies (ICT) infrastructure sector has dramatically expanded over the past decade as the demand for increased digital connectivity has increased from both companies and consumers. Broadband investment has been increasingly associated with positive economic growth and digital connectivity is seen as an essential ingredient with which to increase productivity, employment and create new enterprises. Hence, there is concern that companies and consumers in particular locations are disadvantaged if they are unable to obtain sufficient connectivity. At the present time there has been limited analysis of where new investment has taken place, why it has taken place in specific locations, and what the key economic and socio-economic drivers have been influencing this. The role of regulation in this process is also important to understand.

This article draws on two unique, uncensored infrastructure datasets from the UK's telecommunications regulator Ofcom to assess the factors driving investment in fixed and mobile ICT infrastructure. The fixed infrastructure model utilised modem sync speed measurements from over 20 million premises, aggregated to 7004 Middle Super Output Areas (MSOA) (97.3\%) in England and Wales, to provide comprehensive micro-geographic analysis for the first time. The mobile model employed the average data transfer per premises as a network capacity-demand metric for 173 counties and Unitary Local Authorities (ULAs) (98.3 \%) in England, Scotland and Wales. Using predictors at a range of spatial scales, multilevel modelling utilising Markov Chain Monte Carlo (MCMC) methods was used to estimate both the fixed and mobile broadband infrastructure models.

The results confirm many of the prevailing postulates of existing telecommunications theory, namely, that dense, wealthy and well-educated areas are attractive investment hotbeds for telecommunication technologies. In the UK's fixed ICT infrastructure market, inter-platform competition was found to have a positive impact on investment compared to the mixed results found for intra-platform competition. On the whole, telecommunication investment in the UK appears to be driven by the same drivers as the much documented U.S. case, but further spatially granular research needs to be undertaken to examine the market dynamics between the incumbent and different forms of induced competition across the telecommunication network.
\end{abstract}

Keywords: ICT infrastructure; Fixed \& mobile broadband; Infrastructure investment; Spatial; Urban \& regional economic development

\footnotetext{
*Correspondence: ejo31@cam.ac.uk

'Department of Land Economy, Cambridge Centre for Climate Change

Mitigation Research, University of Cambridge, Cambridge, UK

Full list of author information is available at the end of the article
} 


\section{Background}

The Information and Communication Technologies (ICT) sector has expanded considerably over the past decade as the demand for increased digital connectivity has increased from both companies and consumers. The speed of technical change in both the supply of ICT infrastructure, and the means by which firms and individuals demand digital connectivity services, has been dramatic, leading to a new global epoch of interconnectivity and hence a new stage in contemporary capitalism (Devriendt et al. 2008, Grubesic et al. 2011; Tranos, 2011). Indeed, we have seen the convergence of voice, video and data services heightening the importance of fast and reliable digital connectivity. Broadband investment has been associated with positive economic growth (Holt \& Jamison, 2009; Czernich et al. 2011; Koutroumpis, 2009, Kolko, 2012, Qiang et al. 2009, Röller \& Waverman, 2001), increasing productivity, employment and the creation of new enterprises (Katz, 2009; Malecki \& Moriset 2008; Kandilov \& Renkow, 2010). For example, it has been estimated that firms can increase their productivity by between 7-10 \% regardless of their location (urban versus rural) or the intensity of their information usage (Grimes et al. 2012), providing they have the necessary human capital (Mack \& Faggian, 2013).

There is concern that companies in particular locations are disadvantaged if they are unable to obtain sufficient connectivity. Places with large technological endowments, which include ICT infrastructure, contribute to the vitality of entrepreneurial and innovative activities. This is particularly the case for high-tech industries like software or knowledge-based services which intensely utilise technology (Heger et al. 2011). Indeed, Henderson et al. (2007) identified infrastructure as one of the five key factors driving regional entrepreneurship along with human capital, amenities, financial capital and the local economy. Moreover, connectivity through ICT infrastructure has been found to have a positive impact on innovation, enhancing a region's patenting activities (Vinciguerra et al. 2011). Due to new technological innovations, the emergence of the digital economy has led to new spatial economic industrial location patterns (Feldman, 2002), predominantly reinforcing the existing dominance of cities due to the market and non-market advantages which they purvey (Glaeser et al. 1992; Glaeser, 2010; Glaeser, 2011). Although not always physically visible, leading global cities have reinforced their existing competitive advantage by becoming digital hubs for new technological infrastructures serving the Internet and subsequent digital economy (Tranos 2013). Evidently, a positive evolutionary dynamic is at play.

There is no doubt that the emergence of the digital economy is intrinsically interconnected with the emergence of new telecommunication infrastructure networks. An example being the replacement of copper and coaxial cable by fibre, wireless or other advanced methods of connectivity (Karlsson, 2004). As well as there being fundamental changes in the different transmission mediums used, there are also multiple transmission technologies being newly implemented in the network infrastructure. For example, we have seen advances made in the technologies used at the exchange, as fixed narrowband communications are upgraded to faster variants of broadband Digital Subscriber Line (ADSL, ADSL2+, VDSL, FTTP) or cable technologies. The quality of the connection obtainable over DSL is however highly variant depending particularly on the geographic distance of the premises from the nearest telephone exchange or street cabinet, and therefore how much copper the signal must travel over as a transmission medium (Grubesic \& Horner, 2006). Over copper the broadband signal suffers attenuation as well as interference known as cross-talk, whereby both factors can lead to speed and reliability issues. Next Generation Access (NGA) is a driving force of change in fixed communications and involves the replacement of copper in the network infrastructure with fibre fixed lines to deliver improved connectivity to end users. A comparable dynamic is also seen in wireless methods of transmission as $2 \mathrm{G}$ network coverage is replaced by $3 \mathrm{G}$ and $4 \mathrm{G}$ LTE.

At the present time there has been limited analysis of where new investment has taken place, why it has taken place in specific locations, and what the key economic and socio-economic drivers have been influencing this. Certainly few studies have taken a spatial approach to understanding aspects of the 'digital divide' (Vicente \& López 2011). It is evident that fixed and mobile ICT infrastructure are necessary factors of production required to remain competitive in the contemporary digital economy, and also for consumers to participate in an advanced and modern society. Yet to inform robust decision making we still need to understand the factors that are driving investment at a geographically granular level in ICT infrastructure and the role the regulatory regime has played. This article addresses these issues by drawing on recent experience of the United Kingdom. Section 2 examines the market, regulatory and policy context in which fixed and mobile ICT infrastructure is positioned. Section 3 examines the key factors that are driving broadband demand and Section 4 then reviews the broad contextual background and identifies key research questions. Section 5 sets out the methodology and Section 6 the data used. Section 7 presents model outputs and key findings. Section 8 draws together key conclusions and highlights where further research might usefully be progressed.

\section{Fixed and mobile ICT infrastructure in context}

ICT infrastructure is a classic example of a complex adaptive system, and is comprised of a variety of complementary fixed and mobile, communication and computation 
systems (Vogelsang, 2010). It plays a key role in enabling a wider ICT ecosystem which is itself comprised of an evolving variety of networked elements, platforms, applications, digital services, content and consumer demands (Fransman, 2010; Bauer, 2010). ICT infrastructure is one key component of the fifth Kondratieff long wave the ICT revolution - which has continually been shifting employment patterns towards increasingly informationintensive economic activities. However, the seamless web of digital connectivity services enabling this is merely the end product of a complex process fused together by the regional, national and global investment strategies of network operators and their governing financial actors. Moreover, the deployment of infrastructure and its associated services are intrinsically dependent on a mix of economic, geographic, historical and regulatory factors (Rutherford, 2011). As ICT infrastructure is a necessary fixed factor of production in the contemporary digital economy, it can thus impact on the current and future economic development of different places. Not only can it lead to the production of new goods and services, but it can also horizontally increase the productivity of more industrial sectors across the economy through process and organisational improvements.

In terms of policy, the Digital Agenda for Europe is pivotal in delivering NGA (also known as superfast broadband) which is not just required to nurture the digital economy but has also been heralded to encourage social and economic cohesion (European Commission, 2014). The European Commission wishes to remove the so called "digital divide" and harness ICT to remove barriers between urban and rural areas, central and peripheral locations, and even between social groups within society. Indeed, as broadband access has become more ubiquitous there has been a shift in the focus of policy makers to access quality. Europe has the aspiration of providing Internet access speeds to all EU citizens of 30Mbit/s, with over $50 \%$ of citizens subscribing to a connection over $100 \mathrm{Mbit} / \mathrm{s}$, by 2020 . EU Structural and Rural Development Funds have been utilised to support poorly connected places, yet it was not until recently that the Commission (2014) released its Digital Agenda Toolbox, aiming to help regional and national authorities develop a better understanding of the digital growth potential of the Digital Agenda. ICT infrastructure (along with services, applications and products) plays a central role in the guidance. On the other side of the Atlantic, the Obama administration has followed a similar agenda. Congress approved $\$ 7.2$ billion under the American Recovery and Reinvestment Act of 2009 to enhance broadband infrastructure in regions of poor connectivity. Moves have been made to provide user-friendly tools to help policymakers assess broadband availability in the U.S (e.g. Kolko, 2010). Even with China's dominance in global production, Premier Li Keqiang unveiled a plan to invest $\$ 323$ billion in expanding its fixed and wireless broadband connectivity in order to spur Chinese service sector development (Oughton, 2013).

Traditionally, improvements in infrastructure have been considered to be a classic supply side intervention (McCann, 2013). Thus, improving the physical accessibility of lagging regions has been a central priority of the European Union which has subscribed heavily to this perspective in recent decades (Crescenzi \& Rodríguez-Pose, 2008). However, infrastructure is not the only bottleneck to development as weak education and skills have held back vigorous economic change in lagging regions (Pike et al. 2006). Moreover, in much the same way that roads can work to take economic activity into and out of a region, increases in ICT infrastructure investment have the potential to increase competition in local economies (Rodríguez-Pose, 2002). Frequently the economic benefits of infrastructure investment have often been over estimated for political gains, while costs have been underestimated (Ansar et al. 2014), especially with regard to 'mega' infrastructure projects (Ansar, 2013). Moreover, the bi-directional causality between infrastructure investment and economic growth has long been debated since (Aschauer, 1989), and hence the causal direction does not clearly run from investment to economic growth. This interdependence between supply and demand is what characterises infrastructure research. However, ICT infrastructure endowments still influence corporate decision making, employment and entrepreneurial activity. Hence, Mack \& Grubesic (2014) advocate greater public intervention in private ICT infrastructure markets to overcome disparities in provision.

Infrastructure investment and the revenue generation for network operators are driven by key economic, technological and regulatory parameters in ever competitive markets. The pursuit of financial viability in investment is central, especially in legacy network industries where there are large sunk costs and uncertainties (Tselekounis \& Varoutas, 2013). Viability is also severely impacted on by population density, topology and expected demand, particularly when there is the possibility for new and superior technologies to enter the market (Götz, 2013). The regulatory approach adopted for the fixed telecommunications industry over the past decade in Europe has been attributed (among others) to the work of Cave (2006), whereby competitors in the market have been encouraged to progressively make investments in network assets; thus, 'climbing the ladder of investment'. Cave's perspective is proclaimed to promote consumer welfare through offering choice, variety, competitive prices and increased innovation, by always aiming to induce sustainable infrastructure-based competition, although some have only found weak empirical evidence 
for the existence of this theory (Bacache et al. 2014). The governance and regulatory regime has such a profound impact on investment in NGA that different regimes, from regulatory holidays to risk-sharing among competitors, have been explored (Nitsche \& Wiethaus, 2011; Inderst \& Peitz, 2012). The policy approach to regulating ICT infrastructure is essentially a trade-off between short and longterm policy objectives and whether one wants to achieve static or dynamic investment gains (Bauer, 2010).

Indeed, competition within the industry has also played a critical role, particularly as it has arisen from (a) inter-platform competition (DSL versus cable), (b) facilities-based intra-platform competition (DSL incumbent versus Local Loop Unbundling), or (c) servicesbased intra-platform competition (DSL incumbent retail versus bitstream access \& resale) (Bouckaert et al. 2010). The introduction of intra-platform competition is one of the most recent developments and has resulted in the introduction of the regulatory process of Local Loop Unbundling (LLU). This allows multiple telecommunications operators to use existing connections between the telephone exchange and the consumer's premises, without the need for building additional duplicate infrastructure. As a result, the 'rungs of the ladder' are provided to new entrants who are able to lease access from the incumbent owner of the physical infrastructure network. Yet this regulatory paradigm has not been without criticism (see Bourreau et al. 2010), especially as the intrinsic relationship between access, investment and disparate geographies has on the whole been overlooked. This is especially pertinent in the UK where there has been concern over a lack of broadband access for (predominantly) rural areas. Cave's (2014) recent review highlights the need for regulatory change as over the past decade we have moved from simply unbundling copper to delivering fibre-based NGA.

\section{Related studies on the determinants of ICT infrastructure supply and demand}

Regions vary considerably in their economic endowments and socio-economic characteristics which indeed reflect their ICT requirements. Thus, by way of example, the extensive literature on urban agglomeration espouses the innovation and productivity benefits of firms who locate in urban areas because they have access to a critical mass of specialised suppliers, buyers, thick labour markets as well as infrastructure assets and services (Jacobs, 1969; Brakman et al. 2009; Glaeser, 2010; McCann, 2013). The self-reinforcing effects of agglomeration in cities and regions subsequently lead to a cyclical process where competitive locations reinforce their existing advantage in the business environment through a dynamic, evolutionary feedback process (Martin \& Sunley, 2012). From a theoretical perspective, ICT infrastructure investment focuses on delivering specific services to businesses, residential consumers or both. The increased penetration potential of devices and services resulting from high population densities is a key factor in driving investment, yet the historical legacy of each operator's network continually affects strategy and market behaviour in a path dependent way.

In a spatial analysis of US broadband services Grubesic (2010) identifies the key factors driving the demand for broadband. They are population density, education and income levels, as well as the age of the population. Investment in ICT infrastructure is more likely to take place in locations with larger populations because network operators require a large number of customers who are willing to pay, often premium prices, for new digital connectivity services like broadband. Hence, it is also attractive for locations to have a large number of highly-paid residential consumers who have the necessary disposable income to pay for new services. Although broadband diffusion is often an urban-rural debate, Vicente \& López (2011) argue that it is the cultural and intuitional factors that most impact on adoption. In the US, age and race appear to have an effect on ICT infrastructure investment in the empirical literature, to the extent that younger, whiter populations are correlated with high levels of broadband provision (Grubesic 2006a).

A study by Mack \& Ray (2014) highlights the importance of broadband for Knowledge Intensive Business Services (KIBS) and the operations of service firms. Moreover, the literature shows that KIBS have been found to be a defining element in innovation-oriented European regions and their absence characterises poor performing regions - this highlights their importance for economic development (Corrocher \& Cusmano, 2014). The employees of these firms are also likely to be highly educated and highly technologically savvy to the extent that they consume a wide variety of digital services themselves. Mack \& Grubesic (2009) identified that information, finance \& insurance, and professional, scientific and technical employment are highly correlated with broadband provision. A statistically significant relationship exists between broadband and establishments, but the intensity of this depends on firm size and industry. Smaller businesses are more correlated with broadband provision than medium or large businesses often because operators avoid trying to serve large firms and institutions who seek specialist high-bandwidth infrastructure instead. Total population, median age and household density were also all positive demand-side determinants (Srinuan \& Bohlin, 2013). Grubesic (2006b)) determined that large non-white populations and median age were negative demand-side determinants.

Dauvin \& Grzybowski (2014) estimated broadband diffusion in the EU using NUTS 1 regional data and 
used a range of supply and demand determinant factors to do this. This included infrastructure data on prices, inter-platform and intra-platform competition, along with socio-economic data covering income per capita, number of households, computer penetration, population density and education level. They concluded by emphasising the importance of analysing the determinants of broadband diffusion, especially in terms of competition and regulation, and found that policies which promote both inter- and intra-platform competition are important for broadband diffusion. Supply-side regulatory factors influence the demand position.

The determinants of accessing fixed broadband were modelled at the household level using a demand component by Flamm \& Chaudhuri (2007). They found that in the US this is a function of price, urban or rural location, age, gender, race, marriage status, employment status, income and education. Importantly, they recognised the existence of a 'digital divide' and that poor, less educated and non-white individuals and communities are detrimentally affected as a consequence of a lack of access to digital connectivity. In Sweden, Srinuan et al. (2012) found that price, housing tenure and age were major determinants of broadband connections. Prieger (2013) found that while mobile broadband is less available in rural locations in the US, it still helps to fill the connectivity gap in fixed broadband coverage.

Even within OECD nations the diffusion of broadband occurs at differing rates (Lin \& Wu, 2013), with the likes of Denmark and the Netherlands leading this group of wealthy countries. However take-up in the UK, for example, was modest until recent years. In a study by Bouckaert et al. (2010) the three areas impacting on broadband diffusion in OECD countries were (a) competition variables (inter, facility and services-based platform competition), (b) broadband service variables (speed \& price), and (C) market demographics (population density, population dispersion, GDP \& PC penetration). The results suggest that interplatform competition has been the key driver of broadband penetration, while intra-platform competition has had more modest effects. This study demonstrates that competition and service variables in the supply of infrastructure combine with demand-side factors to influence investment. This implies there is a high degree of interdependency between ICT infrastructure supply and demand. In contrast, Gruber \& Koutroumpis (2013) found little evidence globally, across 167 broadband markets, that inter-platform competition across technologies (e.g. cable) accelerated broadband diffusion, instead pointing to the benefits of inter-firm and intra-platform competition on the incumbent's Digital Subscriber Line (DSL) platform.

\section{The UK context}

Current statistics indicate that the UK, much like mainland Europe, is dominated by DSL technologies. Almost all premises (>99.9 \%) were connected to an ADSLenabled British Telecom (BT) exchange at the end of 2013 for fixed broadband (Ofcom, 2014c) and the majority (95\%) were connected to an LLU-enabled BT local exchange. The regulator estimates that under half of UK premises were able to receive Virgin Media's cable broadband services in June 2014, and $69 \%$ of UK premises were able to receive BT Openreach/Kcom's fibre broadband services. NGA access in 2014 reached $78 \%$ (>20 million) of UK premises. Historically cable has only been available in urban areas. The main cable operator Virgin Media, recently announced a $£ 3$ billion investment plan to upgrade and extend their network to pass another 4 million businesses and households, offering speeds up to $152 \mathrm{Mbit} / \mathrm{s}$. BT - the incumbent operator with the largest market share - is planning to upgrade its network via the deployment of G.fast technology which is claimed to enable 'ultra-fast' speeds up to $500 \mathrm{Mbit} / \mathrm{s}$ within the next decade.

The process of change in the ICT infrastructure sector and what this means for the economic competitiveness of cities and regions has however received little attention, partly because of a lack of available data. The UK's service-led economy is unevenly dominated by London while other regions suffer from ageing industrial structures which are often uncompetitive in today's international marketplace (Gardiner et al. 2013). Global ICT infrastructure gravitates towards London as a mega-cityregion due to its dominance in the advanced producer services industry and here these specialised employment structures co-evolve with changing ICT infrastructure technologies (Reades \& Smith, 2014). Yet away from London, important questions have been raised over the viability of delivering NGA to the remaining population, especially the bottom $10 \%$ of premises, which has risen to the top of the political agenda (Analysys Mason, 2013). Figure 1 illustrates the average sync speed for fixed ICT infrastructure at the Middle Super Output Area (MSOA).

The UK is ranked 8th on the global ICT Development Index (International Telecommunication Union, 2013) and the urgency to maintain a competitive edge is reinforced by the UK's dominance in the service sector. Although this index is based on metrics for infrastructure access, ICT use, ICT skills and ICT impact, the UK is persistently outperformed by the Nordic countries and many of the East Asian fibre nations (such as Japan and Korea). In the Nordic case, this is due to a long tradition of comprehensive state aid broadband policies, supplemented by strong involvement by municipalities and energy companies (Briglauer \& Gugler, 2013), which contrasts strongly with the UK's more Laissez-faire, 'ladder of investment' 


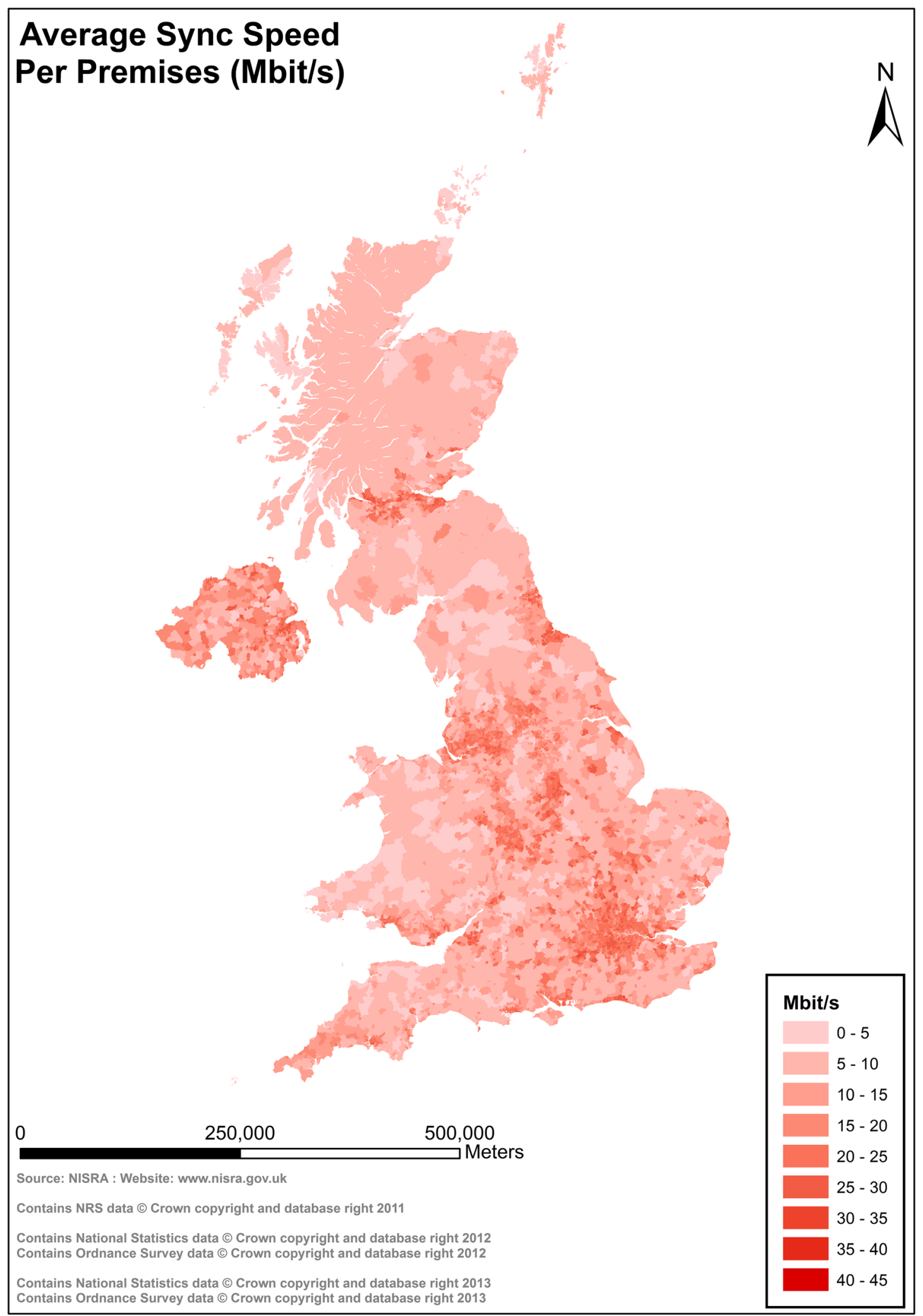

Fig. 1 Average sync speed per premises by MSOA (Mbit/s) 
regulatory approach which aims to create a framework for private investment with limited supply-side subsidies (Ruhle et al. 2011).

The UK has one of the largest weekly Internet usage $(87 \%)$ and broadband take-up rates $(83 \%)$ in the EU (Ofcom, 2014a), and has one of the fastest growing digital economies (Nathan et al. 2013). In fact, the UK leads the G20 nations in this regard with its digital economy expected to contribute $12.4 \%$ of GDP by 2016 (BCG, 2012). The availability and increased penetration of faster broadband speeds has been liberally estimated to add $£ 17$ billion to the UK's annual GVA output by 2024, an increase of $0.07 \%$ (SQW, 2013). Moreover, an exploratory study by Liebenau et al. (2009) found that a $£ 5$ billion investment in UK broadband networks could potentially create 280,500 total jobs, echoing economic analyses carried out elsewhere (e.g. Katz et al. 2010). Figure 2 illustrates the average total mobile data transfer (upload/download) per premises by Unitary Local Authority (ULA).

Access to digital connectivity services has become a popular topic in the British media. A special focus has been placed on (almost always rural) communities being poorly served by fixed broadband and mobile forms of communication. Under New Labour in 2009, the Digital Britain Report (Department for Business, Innovation \& Skills, Department for Culture, Media and Sport, 2009) introduced the Universal Service Broadband Commitment (USBC) which aimed to deliver $2 \mathrm{Mbit} / \mathrm{s}$ to all premises by 2012. Digital connectivity has also been a top priority of the Coalition Government since it took power in 2010 but the date for achieving this policy has been revised many times and currently stands at 2017 . Like many European countries, the UK telecommunication sector is subject to its historical legacy of having a publicly-owned telecommunication monopolist. The incumbent (BT) still owns the largest proportion of the fixed infrastructure. There is ongoing debate over how best to regulate the industry.

\section{Methods}

By employing spatially granular data on ICT infrastructure, the nested structure inherent in the units of observation is amenable to multilevel modelling (MLM). This methodology has been widely applied in urban and regional economics for example to look at inequality (Li \& Wei, 2010), the geography of innovation (Srholec, 2010), human capital in firms (Ployhart \& Moliterno, 2011), and labour market externalities and productivity (Eriksson \& Lindgren, 2008). Using MLM similar individual observations are clustered into higher-level units. Observations which share the same higher-level unit are more likely to have similar values because they share the economic and socio-economic processes that transcend artificial spatial boundaries, indirectly incorporating spatial clustering effects (Lawson et al. 2003). Hence, a primary goal of MLM is to account for non-independence between observations and adjust inferences on parameter estimates accordingly (Browne, 2012). The standard errors produced when using clustered information are generally more conservative than when clustering is ignored. Moreover, MLM in spatial economic research enables the quantification of economic and socio-economic phenomena across different geographic levels enabling us to disentangle different sources of variation whereby each cluster represents a parallel regression line (Goldstein, 1987; Browne, 2012; Arcaya \& Subramanian, 2014). This emphasises the profound impact of different spatial contexts on economic activity. Mack et al. (2011), after studying the importance of broadband provision to knowledge intensive firm location, point to the need for methodologies on this topic to utilise data at a variety of spatial scales to better understand the relationship between firms, industrial sectors and broadband infrastructure. This methodology is able to do this by incorporating predictors at different levels of the hierarchy.

A random-effects multilevel model was selected where the random differentials present are assumed to be outcomes of a process that is predicting them and are conceptualised as coming from a distribution (Goldstein, 2011; Arcaya \& Subramanian, 2014). This results in three practical benefits: (a) information between spatial units is pooled, so all data contribute to the combined estimation of fixed and random parts, (b) statistical power is borrowed from other statistical units to boost robust estimation, and (c) unreliable level one fixed estimates are shrunk towards the overall level one estimates (Ibid.). Given that both models only represent a proportion of the UK, it would be highly desirable to be able to generalise the results. Hence, our interest is primarily in examining the variability across lower and higher units. The challenge for fitting complex MLMs is estimating the data-level regression coefficients along with the group-level model. The most direct way to do this is by using Bayesian inference as it treats the group-level model as 'prior information' in estimating individual-level coefficients (Gelman \& Hill, 2007).

Indeed, recent scientific discourse has focused on the fact that too many studies lack reproducibility. Often when frequentist statistical methodologies are used they can be the source of the problem as classical significance has long been claimed to be biased against the null hypothesis (Edwards, 1965). This leads to false positives in the quest for scientific knowledge which ultimately leads to researchers drawing incorrect inferences. The majority of regional science up until the 1990s was based on frequentist statistics, as detailed by Anselin's (1988) thorough review of the spatial econometric literature. The technique of Markov Chain Monte Carlo (MCMC) estimation has enabled the sophisticated modelling of large data sets with 


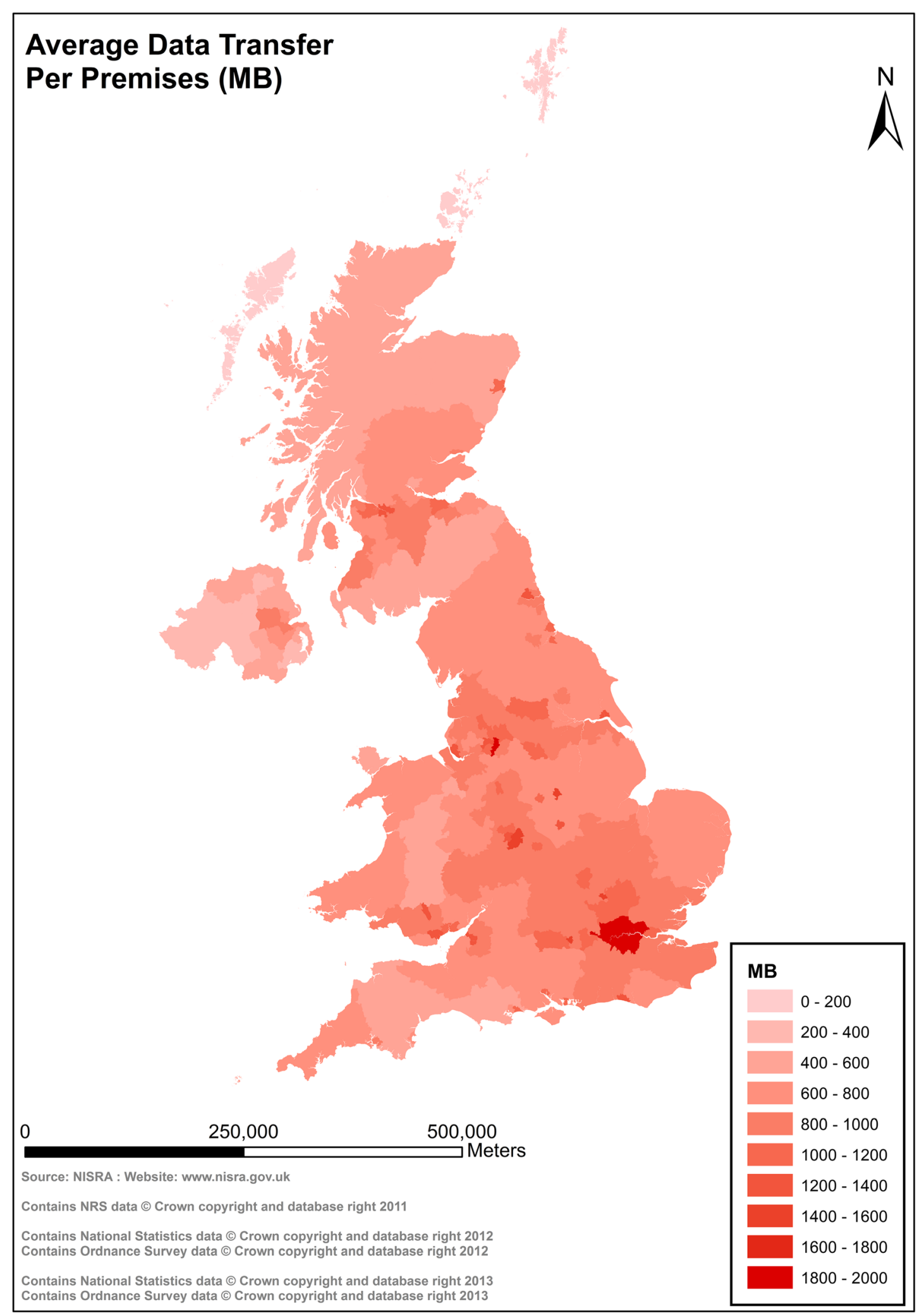

Fig. 2 Average mobile data transfer per premises (MB) (June 2013) 
cross-sectional correlation (Mills \& Parent, 2014), with recent developments enabling Bayesian MLM analysis for complex geographically clustered data (LeSage \& Pace, 2009). The use of MCMC estimation enabled the specification of more complex multilevel models which would not have been possible to estimate using frequentist statistical techniques.

In this article all analyses utilised Bayesian inference using Markov Chain Monte Carlo (MCMC) algorithms in the multilevel modelling software MLwiN 2.30. To reduce burn-in, starting values were obtained for each model using standard Iterative Generalized Least Squares (IGLS)/Restricted Iterative Generalized Least Squares (RIGLS) before running the MCMC sampler with lowinformative priors. Following Gelman et al. (2013), Geyer (2011) and Mills \& Parent (2014) caution was paid to (a) early iterations of the chain being misrepresentative and (b) the Markov chain being autocorrelated. With regard to the former, the early iterations from the chain were discarded, with the burn-in period being set to 5,000 iterations. With regard to the latter, inference from correlated draws is less precise than from independent draws and hence the thinning value was set to 10 to ensure satisfactory sample mixing. A number of pilot runs were carried out to determine these values. According to Gelman et al. (2013) providing the chain has converged, an MCMC sample of 100 independent draws is more than sufficient for accurate posterior inference, although we significantly exceed this number running the chain long enough to generate an effective sample size of $>100,000$ for each parameter. Early iterations of the chain were discarded.

\section{Data}

Although data is generally limited for ICT infrastructure (see Lehr et al. 2008 for a comprehensive discussion), this article draws on two unique infrastructure datasets from the UK's telecommunications regulator Ofcom. Access to sufficiently granular data is one of the largest research challenges facing researchers from drawing more definite conclusions (Holt and Jamison, 2009) and hitherto there has been a lack of comprehensive micro-geographic data for the UK's ICT infrastructure (SQW, 2013:5). This is an improvement on the types of data available in other countries which often contain little to no information on providers, platforms or speeds (Mack et al. 2011).

The dependent variable used in the fixed broadband infrastructure model is the average modem sync speed derived from over 20 million premises measurements and averaged at the MSOA. This data covers the seven main DSL and cable service providers; BT, Virgin Media, EE, O2, KCom, Talk Talk and Sky (Ofcom, 2013). Complete data were generated for 7004 MSOAs (97.3 \%) in England and Wales and all variables were continuous, as detailed in Table 1.
Measuring broadband is of some debate (Bauer et al. 2010), but sync speed measurements are certainly one of the most robust ways of measuring infrastructure capacity (and by proxy investment) as they overcome some of the limitations associated with speed test measurements (as used in other studies e.g. Riddlesden \& Singleton, 2014). Sync speed measures are unique in their ability to provide accurate diagnostics of the capacity between the telephone exchange and the premises (without physically placing a diagnostic box in each premises) and are the favoured metric of the UK's regulator (Ofcom, 2013). The sync speed is the downstream data rate at which the ISP's equipment in the local exchange or cabinet sends data to the customer's broadband modem and represents the highest possible speed at which data can be transferred across the line (Ibid.). This will depend on the technologies enabled at the exchange (ADSL, ADSL2+, VDSL, FTTP, cable), and the quality of the transfer medium between the exchange, cabinet and modem. The data released by Ofcom into the public domain is usually heavily censored but the regulator provided the researchers with uncensored estimates of the average modem speed at the MSOA making this a unique analysis of the UK's ICT infrastructure. While the researchers were provided with a novel and more spatially granular uncensored dataset, this geographic scale still enabled the regulator to protect the market sensitive data they collected from the operators under their legal powers. After obtaining the Ofcom infrastructure data, the rest of the variables were available directly from ONS Nomis with the exception of the population density variable which was constructed using population and surface area measurement data.

The mobile broadband infrastructure model utilised the average data transfer per premises (download and upload) as the dependent variable, which acts as an indicator of network capacity-demand (Ofcom, 2013). This was provided at the ULA level in England, Scotland and Wales. Table 2 describes the continuous variables explored in the mobile broadband infrastructure model, including which level the predictors reside, their data sources and descriptive statistics. After obtaining the Ofcom infrastructure data, the other variables were generated from the same sources as the fixed model, but aggregated in accordance with the relative geography.

\section{Results \& discussion}

Multilevel models were estimated using IGLS/RIGLS for the fixed and mobile infrastructure models respectively, followed by estimation using MCMC methods (Browne \& Rasbash, 2009). Although more complex MLM specifications were explored, the models reported here met all of the necessary MLM assumptions. The Bayesian Deviance Information Criterion (DIC) (a generalisation of Akaike's Information Criterion) was used to compare models as it 
Table 1 Fixed Broadband Model Variables

\begin{tabular}{|c|c|c|c|c|c|c|c|c|}
\hline Variable & Description & Level & Source & Obs. & Mean & Std. Dev. & Min. & Max. \\
\hline Average. $\mathrm{Sp}_{i j}$ & Average fixed broadband speed (Mbits/s) & MSOA & Ofcom 2014a & 7004 & 17.75 & 6.47 & 1.83 & 31.89 \\
\hline Connection. Density $y_{i j}$ & $\begin{array}{l}\text { Total number of connections divided by the total } \\
\text { number of domestic premises }\end{array}$ & MSOA & $\begin{array}{l}\text { Ofcom 2014a/ } \\
\text { OS Codepoint }\end{array}$ & 7004 & 0.72 & 0.09 & 0.32 & 1.83 \\
\hline P.Tert $_{i j}$ & Percentage of tertiary employment (\%) & MSOA & Nomis 2012 & 7004 & 90.8 & 9.12 & 39.52 & 100 \\
\hline P.KIBS $i j$ & $\begin{array}{l}\text { Percentage of employment in Knowledge Intensive } \\
\text { Business Services (KIBS) (\%) }\end{array}$ & MSOA & Nomis 2012 & 7004 & 24.45 & 9.27 & 0 & 82.61 \\
\hline Occupation $_{i j}$ & $\begin{array}{l}\text { Percentage of the population with Level } 3 \& 4 \\
\text { occupations (managers, professionals, skilled trades etc.) } \\
\text { (under the Standard Occupation Classification, 2010) (\%) }\end{array}$ & MSOA & Nomis 2012 & 7004 & 51.47 & 10.8 & 22.8 & 85.7 \\
\hline $\mathrm{PML}_{i j}$ & $\begin{array}{l}\text { Percentage of Medium ( } 50-249 \text { employees) and Large } \\
\text { (250+ employees) Firms using workplaced-based } \\
\text { employment (\%) }\end{array}$ & MSOA & Nomis 2012 & 7004 & 2.32 & 2.58 & 0 & 16.49 \\
\hline Median.Age $_{i j}$ & Median age of the population & MSOA & Nomis 2012 & 7004 & 39.75 & 6.25 & 20 & 63 \\
\hline P.Owner ${ }_{i j}$ & Percentage of home owners (\%) & MSOA & Nomis 2012 & 7004 & 64.48 & 16.9 & 7.3 & 96.5 \\
\hline Students $_{i j}$ & $\begin{array}{l}\text { Percentage of adults (>18 years of age) in full time } \\
\text { education (\%) }\end{array}$ & MSOA & Nomis 2012 & 7004 & 4.92 & 6.53 & 0.8 & 82.5 \\
\hline P.Edu & Percentage of the population with a degree (\%) & MSOA & Nomis 2012 & 7004 & 21.89 & 9.53 & 3.51 & 62.62 \\
\hline P.Claim ${ }_{i j}$ & $\begin{array}{l}\text { Percentage of the working population claiming a state } \\
\text { benefit (\%) }\end{array}$ & MSOA & Nomis 2012 & 7004 & 2.56 & 1.96 & 0.06 & 17.38 \\
\hline P.Non.White $_{i j}$ & Percentage of the population that are non-white (\%) & MSOA & Nomis 2012 & 7004 & 12.9 & 17.52 & 0.4 & 94.4 \\
\hline P.Econ. Active $e_{i j}$ & $\begin{array}{l}\text { Percentage of the population that are economically } \\
\text { active (\%) }\end{array}$ & MSOA & Nomis 2012 & 7004 & 69.69 & 5.72 & 26.8 & 87.7 \\
\hline P.Cable & Percentage of exchanges with cable enabled (\%) & LAD & Sam Knows 2013 & 348 & 57.19 & 40.65 & 0 & 100 \\
\hline P.LLU & $\begin{array}{l}\text { Percentage of exchanges with Local Loop } \\
\text { Unbundling (LLU) (\%) }\end{array}$ & LAD & Sam Knows 2013 & 348 & 78 & 27.35 & 0 & 100 \\
\hline LLU.Count $_{j}$ & $\begin{array}{l}\text { Average number of service providers at LLU enabled } \\
\text { exchanges (\%) }\end{array}$ & $L A D$ & Sam Knows 2013 & 348 & 4.44 & 2.61 & 0 & 9.75 \\
\hline
\end{tabular}


Table 2 Mobile Broadband Model Variables

\begin{tabular}{|c|c|c|c|c|c|c|c|c|}
\hline Variable & Description & Level & Source & Obs & Mean & Std. Dev. & Min. & Max. \\
\hline$\overline{\text { Data }_{i j}}$ & $\begin{array}{l}\text { Average data throughput per premises } \\
\text { (upload \& download) (MB) }\end{array}$ & ULA & Ofcom 2014b & 173 & 610.3 & 168.48 & 256 & 1268 \\
\hline P.Tert ${ }_{i j}$ & Percentage of tertiary employment (\%) & ULA & Nomis 2012 & 173 & 89.22 & 4.69 & 70.88 & 98.24 \\
\hline P.KIBS & $\begin{array}{l}\text { Percentage of employment in Knowledge } \\
\text { Intensive Business Services (KIBS) (\%) }\end{array}$ & ULA & Nomis 2012 & 173 & 11.19 & 5.58 & 3.39 & 30.96 \\
\hline P.ML $L_{i j}$ & $\begin{array}{l}\text { Percentage of Medium (50-249 employees) } \\
\text { and Large ( } 250+\text { employees) Firms using } \\
\text { workplaced-based employment (\%) }\end{array}$ & ULA & Nomis 2012 & 173 & 3.66 & 1.07 & 1.55 & 6 \\
\hline P. Occupation $i j$ & $\begin{array}{l}\text { Percentage of the population with Level } \\
3 \& 4 \text { occupations (managers, professionals, } \\
\text { skilled trades etc.) (under the Standard } \\
\text { Occupation Classification, 2010) (\%) }\end{array}$ & ULA & Nomis 2012 & 173 & 50.01 & 5.2 & 39.3 & 64.8 \\
\hline P.Econ. Active $i j$ & $\begin{array}{l}\text { Percentage of the population that are } \\
\text { economically active (\%) }\end{array}$ & ULA & Nomis 2012 & 173 & 68.79 & 3.28 & 61.1 & 78.4 \\
\hline P.Students $i j$ & $\begin{array}{l}\text { Percentage of schoolchildren and students } \\
\text { (>18 years of age) in full time education (\%) }\end{array}$ & ULA & Nomis 2012 & 173 & 4.93 & 3.4 & 2 & 18.4 \\
\hline Median.Age $_{i j}$ & Median age of the population & ULA & Nomis 2012 & 173 & 40.29 & 3.64 & 29 & 47 \\
\hline Density $_{i j}$ & Population density in each MSOA (KM²) & ULA & Nomis / ONS SAM & 173 & 1155.32 & 1323.73 & 9 & 5285 \\
\hline P.Claim ${ }_{i j}$ & $\begin{array}{l}\text { Percentage of the working population claiming } \\
\text { a state benefit (\%) }\end{array}$ & ULA & Nomis 2012 & 173 & 5.4 & 2.28 & 1.52 & 11.39 \\
\hline P.Edu ${ }_{i j}$ & Percentage of the population with a degree (\%) & ULA & Nomis 2012 & 173 & 21.04 & 5.16 & 12.1 & 41.4 \\
\hline P.Non. White $i j$ & $\begin{array}{l}\text { Percentage of the population that are } \\
\text { non-white (\%) }\end{array}$ & ULA & Nomis 2012 & 173 & 7.9 & 9.07 & 1.08 & 49.48 \\
\hline Gva.Per.Cap $_{j}$ & $\begin{array}{l}\text { Workplace based GVA per capita (income } \\
\text { allocated to the region where the economic } \\
\text { activity took place) ( } £ \text { ) }\end{array}$ & Nuts 1 & ONS, 2012 & 11 & 18714.38 & 2595.74 & 15401 & 37232 \\
\hline Patent. Apps ${ }_{j}$ & Patent applications to the EPO by priority year & Nuts 1 & Eurostat 2011 & 11 & 176.68 & 140.25 & 39.95 & 550.9 \\
\hline
\end{tabular}

Shetland, Orkney and Eileanan Star were outliers and were subsequently excluded

takes into account both model fit and complexity (Spiegelhalter et al. 2002). The average deviance $(\bar{D})$, the deviance of the expected value of the unknown parameters $(D(\bar{\theta}))$ and the effective number of parameters $(p D)$ are also displayed for completeness. For each of the best fitting models the $2.5 \%$, and $97.5 \%$ values of the posterior distribution were extracted to show the $95 \%$ credible interval (CI). We report the results following the format of other Bayesian researchers in the field of regional science (e.g. Parent \& LeSage, 2008), and take guidance from (Kruschke 2011:508) in reporting Bayesian analyses.

\section{Fixed broadband model}

The Bayesian diagnostic results are displayed in Table $3^{2}$ after specifying nine different multilevel random-intercept models for using the fixed broadband data. Predictors were grand mean centred. The first thing to note in Table 3 is that after specifying the empty (null) model, all subsequent model specifications were a considerable improvement. The null model showed that $58 \%$ of the variance in average fixed sync speed arose from inter-class differences, and $42 \%$ arose from intra-class differences. After this, variables defined as important in the existing theory (e.g. employment in services, density and age) were entered into the model. Finally other empirical variables less defined in the literature were entered (e.g. ethnicity).

As there has been a hybridisation of frequentist and Bayesian approaches in MLM, significance values were still included in the results tables. For individual variables the ratio between the coefficient and the standard

Table 3 Fixed Broadband Model Runs and Diagnostics

\begin{tabular}{llllll}
\hline Model & $\bar{D}$ & $D(\bar{\theta})$ & $\mathrm{pD}$ & \multicolumn{2}{l}{$\mathrm{DIC}$} \\
\cline { 5 - 6 } & & & & Value & Ranking \\
\hline Model 1 & 38232.84 & 37640.94 & 591.90 & 38824.74 & 1 \\
Model 2 & 38233.85 & 37642.52 & 591.33 & 38825.18 & 2 \\
Model 3 & 38231.51 & 37637.52 & 593.99 & 38825.51 & 3 \\
Model 4 & 38243.84 & 37653.83 & 590.02 & 38833.86 & 4 \\
Model 5 & 38311.63 & 37720.41 & 591.23 & 38902.86 & 5 \\
Model 6* & 38483.46 & 37920.20 & 563.26 & 39046.73 & 6 \\
Model 7 & 38470.50 & 37893.80 & 576.70 & 39047.20 & 7 \\
Model 8 & 38473.37 & 37897.66 & 575.70 & 39049.07 & 8 \\
Model 9+ & 40249.71 & 39402.10 & 847.61 & 41097.32 & 9 \\
\hline
\end{tabular}

Empty model

*Removed significant variables with coefficients below 0.05 
error was examined closely, as coefficients twice the size of the standard error indicates a significant effect (Wald test). Insignificant variables $(p>0.05)$ were removed from the model. Also, variables with small coefficients $(<0.05)$ were removed, but had the effect of increasing the DIC (Model 6). The specification for the best fitting model (Model 1) is as follows and its posterior distribution has been reported in Table 4 .

$$
\begin{aligned}
& \text { Average.Sp } p_{i j}=\text { Constant }_{i j}+\text { Connection.Density }_{i j} \\
& + \text { P.Tert } t_{i j}+\text { P.ML } L_{i j}+\text { Median.Age } i j \\
& +P . E d u_{i j}+\text { P.Econ.Active } i j \\
& + \text { Occupation }_{i j}+\text { P.Non. White } e_{i j} \\
& + \text { Students }_{i j}+\text { P.Owner }_{i j}+\text { P.Cable }_{j} \\
& + \text { P.LLU }_{j}+\text { LLU.Count }_{j}+u_{j}+e_{i j}
\end{aligned}
$$

Unsurprisingly the connections density (3.53) had the largest impact on the speed, most likely for two reasons. Firstly, this coefficient could have been impacted on by premises being densely located close to the exchange and therefore still achieving acceptable speeds over copper. Indeed, DSL coverage is highly geographically nuanced based on premises location (Grubesic \& Horner, 2006; Grubesic,

\begin{tabular}{|c|c|c|c|c|c|}
\hline Variable & $\begin{array}{l}\text { Model } \\
\text { Parameter }\end{array}$ & Lower $2.5 \%$ & Mean & Upper $97.5 \%$ & Std. \\
\hline Constant & $\beta_{0}$ & 17.68 & 17.87 & 18.05 & 0.09 \\
\hline $\begin{array}{l}\text { Connection. } \\
\text { Density }_{i j}\end{array}$ & $\beta_{1}$ & 1.69 & $3.53^{*}$ & 5.38 & 0.94 \\
\hline P.Tert ${ }_{i j}$ & $\beta_{2}$ & 0.20 & $0.22^{*}$ & 0.23 & 0.01 \\
\hline $\mathrm{PML}_{i j}$ & $\beta_{3}$ & 0.02 & $0.06^{*}$ & 0.10 & 0.02 \\
\hline Median. Age $i j$ & $\beta_{4}$ & -0.18 & $-0.14^{*}$ & -0.10 & 0.02 \\
\hline P.Edu $u_{i j}$ & $\beta_{5}$ & 0.13 & $0.17^{*}$ & 0.21 & 0.02 \\
\hline P.Econ. Active $i j$ & $\beta_{6}$ & 0.10 & $0.13^{*}$ & 0.16 & 0.02 \\
\hline Occupation $_{i j}$ & $B_{7}$ & -0.26 & $-0.23^{*}$ & -0.20 & 0.02 \\
\hline P.Non. White $i j$ & $B_{8}$ & -0.05 & $-0.04^{*}$ & -0.03 & 0.01 \\
\hline Students $s_{i j}$ & $B_{9}$ & 0.01 & $0.03^{*}$ & 0.06 & 0.01 \\
\hline P.Owner ${ }_{i j}$ & $B_{10}$ & 0.00 & $0.02^{*}$ & 0.03 & 0.01 \\
\hline P.Cable ${ }_{j}$ & $B_{11}$ & 0.08 & $0.09^{*}$ & 0.09 & 0.00 \\
\hline P.LLU & $B_{12}$ & 0.00 & $0.02^{*}$ & 0.03 & 0.01 \\
\hline LLU.Count $_{j}$ & $B_{13}$ & -0.62 & $-0.44^{*}$ & -0.26 & 0.09 \\
\hline $\begin{array}{l}\text { Level } 2 \text { Variance } \\
(n=348)\end{array}$ & $\sigma_{j}^{2}$ & 4.02 & 4.58 & 5.18 & 0.35 \\
\hline $\begin{array}{l}\text { Level } 1 \text { Variance } \\
(\mathrm{n}=7004)\end{array}$ & $\sigma_{i j}^{2}$ & 13.27 & 13.75 & 14.25 & 0.25 \\
\hline
\end{tabular}
2008; Grubesic et al. 2010). Perhaps this is suggestive that in future research, it might be more appropriate to use the percentage of postcodes with NGA enabled instead of sync speed measurements as the dependent variable. This would

Table 4 Model 1 Posterior Distribution remove the effect which arises from the geographic distance between the premises and the exchange. This was experimented with in this research but the models using postcode-level data failed to meet the necessary modelling assumptions because of complex level one variance. Another factor is that although the infrastructure might have been upgraded to NGA, you may still have a large number of premises located a long way from the telephone exchange. Therefore, because they are positioned on a very long local loop it affects the bandwidth obtainable and they might be unable to achieve the $2 \mathrm{Mbit} / \mathrm{s}$ target. But secondly, network providers on the whole are more likely to invest the upfront capital cost to provide improved connectivity to dense areas because they can achieve the largest economies of scale with the least risk to their investment (because they have a large pool of customers to attract). As has often been the case in the UK dense urban areas are subsequently more likely to receive priority in the roll out of NGA infrastructure.

Next, the structure of the local economy in terms of service sector employment had a positive impact on the dependent variable (0.22). This could be because (a) services are often information intensive and therefore require more bandwidth, or (b) the employees of these firms are more intensive users of digital connectivity, and this stimulates investment in infrastructure by network providers because there is substantial demand. Similarly, the percentage of medium and large firms had a small but positive impact on average sync speed (0.06), most likely because these firms choose to locate in dense urban areas with well-educated populations, leading to large demand. A significant positive correlation was found between average sync speed and the education of the local population (0.17).

Out of the socio-economic variables we found that areas with a larger percentage of residents in high-level occupations has a negative effect on speed (-0.44) perhaps due to the location decisions of wealthy socio-economic groups choosing more peripheral and sparse sub-urban locations. The median age of the population also had a negative impact on speed (-0.14) and by proxy investment, in line with existing theory. As expected the percentage of economically active residents had a positive impact on the dependent variable (0.13), as did the percentage of students (0.03) and home owners (0.02). The percentage of non-white individuals in a location had a negative impact on sync speed (-0.04), potentially due to deprivation and therefore a lack of market demand for operators to invest.

The percentage of exchanges with cable available had an as expected positive impact (0.09) due to inter-platform competition. Moreover, the percentage of exchanges with LLU enabled also had a positive impact (0.02), but overall the results contrast with the findings of Gruber \& Koutroumpis (2013). Their analysis found that diffusion 
and investment has taken place from intra-platform competition and less so from inter-platform competition, but it might be that the UK does not follow the same trend. It was surprising to find that the number of LLU operators at an exchange had a negative impact on speed (-0.44), implying on face value that more intraplatform competition leads to lower speeds. However, there are two potential explanations for this finding. Firstly, this negative correlation could be due to LLU operators being attracted to providing services in exchanges with the largest number of lines attached. More lines could lead to increased technological strain on the infrastructure through contention, cross-talk signal attenuation and due to physical space limits having more premises located on copper lines far away from the exchange. Secondly, an alternative explanation is that the larger the number of resellers using the incumbent's infrastructure via LLU, the more the incumbent is deterred from investing in NGA, as they would be less likely to reap full rewards from their investment. If this second explanation was true then the market strategy for the incumbent's DSL platform might be to directly compete with cable through NGA investment, but leave exchanges with a large LLU presence for investment at a later stage. Further analysis on this topic could be carried out with the data used here and could prove of great importance in explaining firstly this result and secondly the investment dynamics between the incumbent and other service providers. Ranking the number of lines attached to each exchange and examining the location characteristics of different parts of the distribution would prove a useful starting point.

\section{Mobile broadband infrastructure model}

The Bayesian diagnostic results are displayed in Table 5 after specifying nine different multilevel randomintercept models using the mobile broadband data. These models all had ULAs clustered within NUTS 1 Regions. All variables were log transformed and the dependent variable was normalised around the mean. The first thing to note in Table 5 is that after specifying the empty (null) model, all subsequent model specifications were a considerable improvement. The null model showed that $24 \%$ of the variance in data traffic arose from inter-class differences, and $76 \%$ arose from intra-class differences.

The approach used for model specification was identical to the approach used for the fixed broadband model. As we can see from Table 5, the model specifications using the predictor variables were a much better fit than the empty (null) model. As before, insignificant variables $(p>0.05)$ were removed from the model along with variables with small coefficients $(<0.05)$. Model 2 had GVA.Per.Capita removed as it was insignificant but had a larger DIC
Table 5 Mobile Broadband Model Runs and Diagnostics

\begin{tabular}{llllll}
\hline Model & $\bar{D}$ & $D(\bar{\theta})$ & $\mathrm{pD}$ & \multicolumn{2}{l}{ DIC } \\
\cline { 5 - 6 } & & & & Value & Ranking \\
\hline Model 1 & -230.31 & -243.42 & 13.110 & -217.20 & 1 \\
Model 2* & -228.30 & -239.84 & 11.54 & -216.76 & 2 \\
Model 3 & -229.43 & -243.21 & 13.780 & -215.65 & 3 \\
Model 4 & 231.23 & -247.74 & 16.500 & -214.73 & 4 \\
Model 5 & -229.52 & -245.33 & 15.810 & -213.72 & 5 \\
Model 6 & -226.70 & -239.88 & 13.180 & -213.52 & 6 \\
Model 7 & -225.46 & -238.97 & 13.510 & -211.94 & 7 \\
Model 8 & -156.06 & -166.14 & 10.080 & -145.98 & 8 \\
Model 9 & -7.37 & -16.94 & 9.57 & 2.19 & 9 \\
\hline
\end{tabular}

${ }^{+}$Empty model

*Removed GVA.Per.Cap as $p>0.05$

than Model 1 when it was left in. Consequently, the specification for the best fitting model (Model 1) is as follows and its posterior distribution has been reported in Table 6.

$$
\begin{aligned}
\text { Log.Data }_{i j} & =\text { Constant }_{i j}+\text { Log.P.Tert }_{i j} \\
& + \text { Log.P.ML } L_{i j}+\text { Log.Density }_{i j} \\
& + \text { Log.Median.Age } i j+\text { Log.P.Non.White }_{i j} \\
& + \text { Log.Gva.Per.Cap } \\
& +u_{j}+e_{i j}
\end{aligned}
$$

Table 6 shows that the largest effect was from median age $(-0.87)$ which had a negative effect on the network capacity-demand metric used as the dependent variable. This is in line with existing theory in that younger demographics are often early adopters of new technologies and consequently they are likely to use them more intensively than older demographics. Areas with younger populations therefore provide larger markets for mobile

\begin{tabular}{|c|c|c|c|c|c|}
\hline Variable & $\begin{array}{l}\text { Model } \\
\text { parameter }\end{array}$ & Lower $2.5 \%$ & Mean & Upper $97.5 \%$ & Std. \\
\hline Constant & $\beta_{0}$ & -4.37 & -1.17 & 1.83 & 1.89 \\
\hline Log.P.Tert $_{i j}$ & $\beta_{1}$ & 0.11 & $0.52^{*}$ & 0.94 & 0.21 \\
\hline Log.P.ML $_{i j}$ & $\beta_{2}$ & 0.03 & $0.15^{*}$ & 0.27 & 0.06 \\
\hline Log.Density $_{i j}$ & $\beta_{3}$ & 0.02 & $0.04^{*}$ & 0.07 & 0.01 \\
\hline Log.Median.Age ${ }_{i j}$ & $\beta_{4}$ & -1.31 & $-0.87^{*}$ & -0.42 & 0.23 \\
\hline Log.P.Non.White $_{i j}$ & $\beta_{5}$ & 0.01 & $0.06^{*}$ & 0.1 & 0.02 \\
\hline Log.Gva.Per.Cap ${ }_{j}$ & $\beta_{6}$ & -0.10 & 0.15 & 0.45 & 1.14 \\
\hline $\begin{array}{l}\text { Level } 2 \text { Variance }{ }^{a} \\
(n=10)\end{array}$ & $\sigma_{j}^{2}$ & 0.00 & 0.00 & 0.01 & 0.00 \\
\hline $\begin{array}{l}\text { Level } 1 \text { Variance }{ }^{a} \\
(n=173)\end{array}$ & $\sigma_{i j}^{2}$ & 0.01 & 0.02 & 0.02 & 0.00 \\
\hline
\end{tabular}
network operators to target. It is logical that infrastructure capacity will attempt to follow demand and

Table 6 Model 1 Parameters and Posterior Distribution

${ }^{*} p<0.05$

${ }^{a}$ Variance is the estimated parameter Results rounded to 2 decimal places 
therefore we can deduce that there is likely to be greater investment in areas with younger demographics. The next largest effect was from service sector employment (0.52) in which we can draw inferences between service firms being more information intensive and their employees being more technologically savvy than in other sectors. Moreover, as was evident with the fixed ICT infrastructure model, the percentage of medium and large firms has a positive (albeit marginal) impact (0.15) on the dependent variable.

In terms of socio-economic variables the percentage of non-white individuals differed significantly between the fixed broadband and mobile broadband models. Whereas ethnic diversity had a marginal negative impact in the fixed ICT infrastructure model $(-0.04)$, it had a marginal positive impact in the mobile ICT infrastructure model (0.06). This result might be due to mobile connectivity functioning as a gateway technology for broadband use. This has been found in deprived urban communities because smaller upfront investment is required for mobile devices (Mossberger et al. 2012).

Density appeared to have less of an impact (0.04) on the dependent variable than some of the other metrics used, which could be attributable to mobile technologies being able to cover larger geographical areas with lower capital investment costs than fixed ICT infrastructure. If so, then the technological differences between these infrastructures indicate that mobile (such as $4 \mathrm{G}$ and beyond) is a likely short-term solution to connecting those places which currently cannot meet the $2 \mathrm{Mbit} / \mathrm{s}$ UK target. In comparison with the fixed model, a larger number of variables were dropped from the mobile infrastructure analysis. Further research needs to analyse the base mobile data from Ofcom, in order to explore these issues in greater spatial granularity. Moreover, there is also a time series developing which would enable greater investigation of directional causality and dynamics in mobile ICT infrastructure supply and demand. Understanding this dynamic would enable more robust causal inferences to be drawn as these are hard to address from cross-sectional data.

\section{Conclusions}

This article set out to examine the supply and demand factors that have driven investment in fixed and mobile ICT infrastructure utilising a spatially granular approach. It did this by analysing a novel, uncensored dataset for the first time from the UK's telecommunication regulator and then developing a multilevel modelling approach which would enable variables to be incorporated at a variety of spatial scales. The use of MCMC estimation enabled the specification of more complex multilevel models which would not have been possible to estimate using frequentist statistical techniques. The fixed broadband infrastructure model generally confirmed many of the existing postulates of existing telecommunications theory - that dense, wealthy and welleducated areas are attractive investment hotbeds for telecommunication technologies. The results showed that the actual economic structure of a local economy, in terms of service sector employment, had a positive impact on investment. In terms of supply, interplatform competition appears to have had a marginal positive impact on average speed and investment, while intra-platform competition showed mixed results.

On the whole, the results were comparable across the fixed and mobile models, although the coefficients were larger in the mobile model. The only diverging results were for population density and ethnicity. The inherent distinction between how fixed and mobile technologies function explains why density had a larger positive impact in the fixed model. The ethnic diversity indicator was the only variable which was profoundly different in that it had a negative effect on investment in fixed broadband infrastructure, and a positive effect in the mobile model. This likely relates to socio-economic disparities and the fact that those in deprived areas are more likely to use mobile connectivity as a gateway technology because mobile devices are a low cost way to connect.

On the whole, telecommunication investment in the UK appears to be driven by the same drivers as the much documented U.S. case, but further research needs to be undertaken which examines the market dynamics between the incumbent and different forms of induced competition across different layers of the telecommunication network. From the results found, the recent announcement that the dominant cable operator is expanding its network reach to four million new premises is likely to have a positive effect on fixed broadband speed due to increased inter-platform competition. In terms of developing public policies which overcome the digital divide, further analysis needs to be conducted which focuses on the availability of digital connectivity in areas of ethnic diversity. While mobile connectivity helps to address the disparity in fixed ICT infrastructure, mobile has however traditionally been inferior to fixed forms of connectivity. In terms of economic development initiatives, given that the supply of ICT infrastructure was correlated with service sector employment, and medium and large firms, there should be a focus on (a) locations with predominantly primary or secondary employment, and (b) connectivity for SMEs. As these infrastructures are necessary factors of production required to remain competitive in the contemporary digital economy greater steps need to be taken to understand investment decisions at a geographically granular level in ICT infrastructure. 


\section{Endnotes}

${ }^{1}$ See Bourreau et al. 2010 for a critical review and also Cave (2014) for a discussion of how the telecommunications sector has changed since the theory was first conceptualised.

${ }^{2}$ Fixed-effects models were explored in the analysis however they had a minimal impact on the coefficients, standard errors and were generally less effective fitting the data than random-intercept models.

\section{Abbreviations}

BT: British Telecom; DIC: Deviance Information Criterion; DSL: Digital Subscriber Line; ICT: Information and Communication Technologies: IGLS: Iterative Generalized Least Squares; KIBS: Knowledge Intensive Business Services; LLU: Local Loop Unbundling; MCMC: Markov Chain Monte Carlo; MLM: Multilevel Modelling; MSOA: Middle Super Output Areas; NGA: Next Generation Access; RIGLS: Restricted Iterative Generalized Least Squares; USBC: Universal Service Broadband Commitment.

\section{Competing interests}

The authors declare that they have no competing interests.

\section{Authors' contributions}

EO conducted the modelling work and wrote up the first draft of the article. PT edited the article and refined the literature review, aims and results. DA generated the choropleth maps and helped to prepare data for the analysis. All authors read and approved the final manuscript.

\section{Acknowledgements}

The authors would like to thank all participants of the ITRC Economics Conference at St. Catharine's College, Cambridge, along with the positive recommendations made by two anonymous reviewers. We are very grateful to Richard Moore and Satya Ammu at Ofcom, and Neil Campbell at Sam Knows, and for providing valuable data without which this work would not have been possible. We must also thank Professor Bob Haining, Professor Geoffrey Hewings, Dr Louise Corrado and Dr. Jan Zirk-Sadowski for constructive advice on the methodology. lan Adkins and Dr James Allen of Analysys Mason also provided valuable advice. The research reported in this article was part of the UK Infrastructure Transitions Research Consortium (ITRC) funded by the Engineering and Physical Sciences Research Council under Programme Grant EP/I01344X/1.

\section{Author details}

${ }^{1}$ Department of Land Economy, Cambridge Centre for Climate Change Mitigation Research, University of Cambridge, Cambridge, UK. ²Department of Land Economy, University of Cambridge, Cambridge, UK. ${ }^{3}$ School of Civil Engineering and Geosciences, University of Newcastle, Newcastle, UK.

Received: 15 August 2014 Accepted: 15 May 2015

Published online: 07 July 2015

\section{References}

Ansar A (2013) Location decisions of large firms: analyzing the procurement of infrastructure services. J Econ Geogr 13:823-844. doi:10.1093/jeg/lbs042

Ansar A, Flyvbjerg B, Budzier A, Lunn D (2014) Should we build more large dams? The actual costs of hydropower megaproject development. Energy Policy 69:43-56. doi:10.1016/j.enpol.2013.10.069

Anselin, L, (1988) Spatial Econometrics: Methods and Models. Dordrecht, The Netherlands: Kluwer Academic Publishers.

Arcaya M, Subramanian PSV (2014) Ecological inferences and multilevel studies. In M. M. Fischer \& P. Nijkamp, eds. Handbook of Regional Science. Berlin: Springer Berlin Heidelberg, pp. 1335-1363. Available at: http:// link.springer.com/referenceworkentry/10.1007/978-3-642-23430-9_74 [Accessed June 27, 2014]

Aschauer, DA, (1989) Is public expenditure productive? Journal of Monetary Economics 23, 177-200. doi:10.1016/0304-3932(89)90047-0

Bacache M, Bourreau M, Gaudin G (2014) Dynamic Entry and Investment in New Infrastructures: Empirical Evidence from the Fixed Broadband Industry. Rev Ind Organ 44:179-209. doi:10.1007/s11151-013-9398-4
Bauer JM (2010) Regulation, public policy, and investment in communications infrastructure. Telecommun Policy, Balancing Competition Regulation 34:65-79. doi:10.1016/j.telpol.2009.11.011

Bauer S, Clark D, Lehr W (2010) Understanding Broadband Speed Measurents, MIT Internet Traffic Analysis Study (MITAS) Working Paper Series

Boston Consulting Group (2012) The \$4.2 trillion opportunity: The internet economy in the G-20, Boston: Boston Consulting Group. Available at: https:// publicaffairs.linx.net/news/wpcontent/uploads/2012/03/ bcg_4trillion_opportunity.pdf [Accessed March 1, 2014].

Bouckaert J, van Dijk T, Verboven F (2010) Access regulation, competition, and broadband penetration: An international study. Telecommun Policy 34:661-671. doi:10.1016/j.telpol.2010.09.001

Bourreau M, Doğan P, Manant M (2010) A critical review of the "ladder of investment" approach. Telecommun Policy 34:683-696. doi:10.1016/ j.telpol.2010.09.002

Brakman, S, Garretsen, H, Marrewijk, C van, (2009) The New Introduction to Geographical Economics. Cambridge University Press.

Briglauer W, Gugler K (2013) The deployment and penetration of high-speed fiber networks and services: Why are EU member states lagging behind? Telecommun Policy, Regulating and investment in new communications infrastructure Understanding ICT adoption and market trends: Papers from recent European ITS regional conferences 37:819-835. doi:10.1016/j.telpol.2013.05.003

Browne WJ (2012) MCMC Estimation in MLwiN (Version 2.26), Centre for Multilevel Modelling. University of Bristol, Bristol

Browne WJ, Rasbash J (2009) MCMC estimation in MLwiN, Bristol: Citeseer Available at: http://citeseerx.ist.psu.edu/viewdoc/download?doi=10.1.1. 180.6971\&rep=rep1\&type=pdf [Accessed May 22, 2014].

Cave M (2006) Encouraging infrastructure competition via the ladder of investment. Telecommun Policy 30:223-237. doi:10.1016/j.telpol.2005.09.001

Cave, M., 2014. The ladder of investment in Europe, in retrospect and prospect. Telecommunications Policy. doi:10.1016/j.telpol.2014.04.012.

Commission E (2014) The Digital Agenda Toolbox. European Commisson, Luxembourg

Corrocher N, Cusmano L (2014) The "KIBS Engine" of Regional Innovation Systems: Empirical Evidence from European Regions. Reg Stud 48:1212-1226. doi:10.1080/00343404.2012.731045

Crescenzi R, Rodríguez-Pose A (2008) Infrastructure Endowment and Investment as Determinants of Regional Growth in the European Union (EIB Paper No. 8/2008), European Investment Bank, Economics Department

Czernich N, Falck O, Kretschmer T, Woessmann L (2011) Broadband Infrastructure and Economic Growth*. Econ J 121:505-532. doi:10.1111/j.1468-0297.2011.02420.x

Dauvin M, Grzybowski L (2014) Estimating broadband diffusion in the EU using NUTS 1 regional data. Telecommun Policy 38:96-104. doi:10.1016/ j.telpol.2013.05.006

Department for Business, Innovation \& Skills, Department for Culture, Media and Sport (2009) Digital Britain. BIS \& DCMS, London

Devriendt L, Derudder B, Witlox F (2008) Cyberplace and Cyberspace: Two Approaches to Analyzing Digital Intercity Linkages. J Urban Technol 15:5-32. doi:10.1080/10630730802401926

Edwards W (1965) Tactical note on the relation between scientific and statistical hypotheses. Psychol Bull 63:400-402. doi:10.1037/h0021967

Eriksson R, Lindgren U (2008) Localized mobility clusters: impacts of labour market externalities on firm performance. J Econ Geogr Ibn025. doi:10.1093/jeg/lbn025

Feldman MP (2002) The Internet revolution and the geography of innovation. Int Soc Sci J 54:47-56. doi:10.1111/1468-2451.00358

Flamm K, Chaudhuri A (2007) An analysis of the determinants of broadband access. Telecommun Policy 31:312-326. doi:10.1016/j.telpol.2007.05.006

Fransman M (2010) The New ICT Ecosystem: Implications for Policy and Regulation. Cambridge University Press, Cambridge

Gardiner B, Martin R, Sunley P, Tyler P (2013) Spatially unbalanced growth in the British economy. J Econ Geogr 13:889-928. doi:10.1093/jeg/lbt003

Gelman, A, Carlin, JB, Stern, HS, Dunson, DB, Vehtari, A, Rubin, DB, (2013) Bayesian Data Analysis, Third Edition, 3 edition. ed. Chapman and Hall/CRC, Boca Raton.

Gelman A, Hill J (2007) Data analysis using regression and multilevel/hierarchical models, Cambridge, U.K.: Cambridge University Press. Available at: http:// books.google.co.uk/books?hl=en\&lr=\&id=c9xLKzZWoZ4C\&oi=fnd\&pg= PR17\&dq=Gelman+\%26+Hill+\&ots=baM3R-Tnpb\&sig=sbn26tbLtE4uh KHbiEOZnOMUpCs [Accessed May 22, 2014] 
Geyer, (2011) Introduction to Markov Chain Monte Carlo, In: Brooks, S., Gelman, A., Jones, G., Meng, X. (Eds.), Handbook of Markov Chain Monte Carlo. CRC Press.

Glaeser E (2011) Triumph of the City: How our Greatest Invention Makes us Richer, Smarter, Greener. Healthier and Happier, Pan Macmillan, London

Glaeser E, Kallal HD, Scheinkman JA, Shleifer A (1992) Growth in Cities. J Polit Econ 100:1126-1152

Glaeser EL (2010) Agglomeration economics, Chicago: University of Chicago Press. Goldstein H (1987) Multilevel models in educational and social research. Griffin [and] Oxford University Press, London.

Goldstein H (2011) Multilevel statistical models, London: John Wiley \& Sons.

Götz G (2013) Competition, Regulation, and Broadband Access to the Internet. Telecommun Policy 37:1095-1109. doi:10.1016/j.telpol.2013.03.001

Grimes A, Ren C, Stevens P (2012) The need for speed: impacts of internet connectivity on firm productivity. J Prod Anal 37:187-201. doi:10.1007/ s11123-011-0237-z

Gruber H, Koutroumpis P (2013) Competition enhancing regulation and diffusion of innovation: the case of broadband networks. J Regul Econ 43:168-195. doi:10.1007/s11149-012-9205-4

Grubesic TH (2006) A spatial taxonomy of broadband regions in the United States. Inf Econ Policy 18:423-448. doi:10.1016/j.infoecopol.2006.05.001

Grubesic TH (2008) The spatial distribution of broadband providers in the United States: 1999-2004. Telecommun Policy 32:212-233. doi:10.1016/j.telpol.2008.01.001

Grubesic TH (2010) Efficiency in broadband service provision: A spatial analysis. Telecommun Policy 34:117-131. doi:10.1016/j.telpol.2009.11.017

Grubesic TH, Horner MW (2006) Deconstructing the divide: extending broadband xDSL services to the periphery. Environ Plan B 33:685-704. doi:10.1068/ b32058

Grubesic, TH, Matisziw, TC, Murray, A, (2010) Market Coverage and Service Quality in Digital Subscriber Lines Infrastructure Planning. International Regional Science Review 0160017610386479. doi:10.1177/0160017610386479

Grubesic, TH, Matisziw, TC \& Ripley, DAJ, (2011) Approximating the geographical characteristics of Internet activity. Journal of Urban Technology, 18(1):51-71.

Heger D, Rinawi M, Veith T (2011) The effect of broadband infrastructure on entrepreneurial activities: The case of Germany (ZEW Discussion Paper No. 11-081), ZEW - Zentrum für Europäische Wirtschaftsforschung/Center for European Economic Research

Henderson J, Low SA, Weiler S (2007) The Drivers of Regional Entrepreneurship in Rural and Metro Areas, in: Entrepreneurship and Local Economic Development, Lexington Books

Holt L, Jamison M (2009) Broadband and contributions to economic growth: Lessons from the US experience. Telecommun Policy 33:575-581. doi:10.1016/j.telpol.2009.08.008

Inderst R, Peitz M (2012) Network investment, access and competition. Telecommun Policy, Regulation and competition in communications markets 36:407-418. doi:10.1016/j.telpol.2011.12.007

International Telecommunication Union, 2013. ITU Statistics [WWW Document]. ITU. URL http://www.itu.int/en/ITU-D/Statistics/Pages/stat/default.aspx (accessed 11.25.13).

Jacobs J (1969) The economy of cities, London: J. Cape.

Kandilov IT, Renkow M (2010) Infrastructure Investment and Rural Economic Development: An Evaluation of USDA's Broadband Loan Program. Growth Change 41:165-191. doi:10.1111/j.1468-2257.2010.00524.x

Karlsson, C., 2004. ICT, Functional Urban Regions and the New Economic Geography (Working Paper Series in Economics and Institutions of Innovation No. 14). Royal Institute of Technology, CESIS - Centre of Excellence for Science and Innovation Studies.

Katz RL (2009) The Economic and Social Impact of Telecommunications Output A Theoretical Framework and Empirical Evidence for Spain. Intereconomics 44:41-48

Katz RL, Vaterlaus S, Zenhäusern P, Suter S (2010) The impact of broadband on jobs and the German economy. Intereconomics 45:26-34. doi:10.1007/ s10272-010-0322-y

Kolko J (2010) A new measure of US residential broadband availability. Telecommun Policy 34:132-143. doi:10.1016/j.telpol.2009.11.015

Kolko J (2012) Broadband and local growth. J Urban Econ 71:100-113. doi:10.1016/j.jue.2011.07.004

Koutroumpis P (2009) The economic impact of broadband on growth: A simultaneous approach. Telecommun Policy 33:471-485. doi:10.1016/ j.telpol.2009.07.004
Kruschke JK, author (2011) Doing Bayesian data analysis: a tutorial with R and BUGS, Burlington, MA: Academic Press.

Lawson AB, Browne WJ, Rodeiro CLV (2003) Disease mapping with WinBUGS and MLwiN, Hoboken, NJ: John Wiley \& Sons.

Lehr W, Smith-Grieco T, Rusi Woo G (2008) Broadband Metrics Best Practices: Review and Assessment. MIT, Boston

LeSage J, Pace RK (2009) Introduction to Spatial Econometrics. CRC Press, Boca Raton

Liebenau, J., Atkinson, R., Kärrberg, P., Castro, D., Ezell, S., 2009. The UK's digital road to recovery [WWW Document]. URL http://www.Ise.ac.uk/collections/ enterpriseLSE/ (accessed 2.25.15)

Lin M, Wu F (2013) Identifying the determinants of broadband adoption by diffusion stage in OECD countries. Telecommun Policy 37:241-251. doi:10.1016/j.telpol.2012.06.003

Li Y, Wei YHD (2010) The spatial-temporal hierarchy of regional inequality of China. Appl Geogr 30:303-316. doi:10.1016/j.apgeog.2009.11.001

Mack EA, Anselin L, Grubesic TH (2011) The importance of broadband provision to knowledge intensive firm location. Regional Sci Policy Practice 3:17-35. doi:10.1111/j.1757-7802.2011.01026.x

Mack EA, Grubesic TH (2009) Broadband Provision and Firm Location in Ohio: An Exploratory Spatial Analysis. Tijdschr Econ Soc Geogr 100:298-315. doi:10.1111/j.1467-9663.2008.00487.x

Mack EA, Grubesic TH (2014) US broadband policy and the spatio-temporal evolution of broadband markets. Regional Science Policy \& Practice n/a-n/a. doi:10.1111/rsp3.12042.

Mack EA, Rey SJ, (2014) An econometric approach for evaluating the linkages between broadband and knowledge intensive firms. Telecommunications Policy, 38(1), pp.105-118.

Mack E, Faggian A (2013) Productivity and Broadband The Human Factor. Int Reg Sci Rev 36:392-423. doi:10.1177/0160017612471191

Malecki, E.J., Moriset, B. 2008. The digital economy: business organisation, production processes and regional developments. Routledge, London

Martin R, Sunley P, (2012) Forms of emergence and the evolution of economic landscapes. Journal of Economic Behavior \& Organization, 82(2-3), pp.338-351.

Mason A (2013) Cities Project. Analysys Mason, Manchester.

McCann P, (2013) Modern urban and regional economics 2nd ed., Oxford: OUP Oxford.

Mills JA, Parent O (2014) Bayesian MCMC estimation. In M. M. Fischer \& P. Nijkamp, eds. Handbook of Regional Science. Berlin: Springer Berlin Heidelberg, pp. 1571-1595. Available at: http://link.springer.com/ referenceworkentry/10.1007/978-3-642-23430-9 89 [Accessed June 27, 2014]

Mossberger K, Tolbert CJ, Bowen D, Jimenez B (2012) Unraveling Different Barriers to Internet Use Urban Residents and Neighborhood Effects. Urban Aff Rev 48:771-810. doi:10.1177/1078087412453713

Nathan M, Rosso A, Gatten T, Majmudar P, Mitchell A (2013) Measuring the UK's Digital Economy With Big Data. National Institute of Economic and Social Research, London

Nitsche R, Wiethaus $L$ (2011) Access regulation and investment in next generation networks - A ranking of regulatory regimes. Int J Ind Organ 29:263-272. doi:10.1016/j.jindorg.2010.07.002

Nomis (2012) Official labour market statistics. Available at: https:// www.nomisweb.co.uk/ [Accessed May 29, 2015]

Ofcom, 2014a. Fixed Broadband Data [WWW Document]. URL http://media.ofcom.org.uk/facts/ (accessed 12.11.13).

Ofcom, 2014b. Mobile Communications Data [WWW Document]. URL http://media.ofcom.org.uk/facts/ (accessed 12.11.13).

Ofcom (2014c) The Communications Market Report 2014. Ofcom, London

Ofcom (2013) Infrastructure Report: 2013 Update. Ofcom, London

ONS (2012) Internet Access - Households and Individuals, 2012. Office of National Statistics, Cardiff

Oughton E, (2013) Connecting China's Broadband Ambitions to Development. East Asia Forum.

Parent O, LeSage JP (2008) Using the variance structure of the conditional autoregressive spatial specification to model knowledge spillovers. J Appl Econ 23:235-256. doi:10.1002/jae.981

Pike A, Pose AR, Tomaney J (2006) Local and regional development, London: Routledge.

Ployhart RE, Moliterno TP (2011) Emergence of the Human Capital Resource: A Multilevel Model. ACAD MANAGE REV 36:127-150

Prieger JE (2013) The broadband digital divide and the economic benefits of mobile broadband for rural areas. Telecommun Policy 37:483-502. doi:10.1016/j.telpol.2012.11.003 
Qiang, C.Z., Rossotto, C.M. \& Kimura, K., 2009. Economic impacts of broadband. In 2009 Information and Communications for Development: Extending Reach and Increasing Impact. Washington D.C.: World Bank Publications.

Reades J, Smith DA (2014) Mapping the "Space of Flows": The Geography of Global Business Telecommunications and Employment Specialization in the London Mega-City-Region. Reg Stud 48:105-126. doi:10.1080/ 00343404.2013.856515

Riddlesden D, Singleton AD (2014) Broadband speed equity: A new digital divide? Appl Geogr 52:25-33. doi:10.1016/j.apgeog.2014.04.008

Rodríguez-Pose A (2002) The European Union: economy, society, and polity. Oxford University Press, Oxford; New York

Röller L-H, Waverman L (2001) Telecommunications Infrastructure and Economic Development: A Simultaneous Approach. Am Econ Rev 91:909-923

Ruhle, E.-O., Brusic, l., Kittl, J., Ehrler, M., 2011. Next Generation Access (NGA) supply side interventions-An international comparison. Telecommunications Policy, PUBLIC SUPPORT FOR THE DEPLOYMENT OF NEXT GENERATION ACCESS NETWORKS: WHY, WHEN, HOW 35, 794-803. doi:10.1016/j.telpol.2011.06.001

Rutherford J (2011) Rethinking the Relational Socio-Technical Materialities of Cities and ICTs. J Urban Technol 18:21-33. doi:10.1080/10630732.2011.578407

Spiegelhalter DJ, Best NG, Carlin BP, Van Der Linde A (2002) Bayesian measures of model complexity and fit. J R Stat Soc Ser B Stat Methodol 64:583-639. doi:10.1111/1467-9868.00353

SQW (2013) UK Broadband Impact Study. SQW, Cambridge

Srholec M (2010) A Multilevel Approach to Geography of Innovation. Reg Stud 44:1207-1220 doi:10.1080/00343400903365094

Srinuan C, Bohlin E (2013) Analysis of fixed broadband access and use in Thailand: Drivers and barriers. Telecommunications Policy, CONVERGENCE IN THE DIGITAL AGE 37:615-625. doi:10.1016/j.telpol.2013.03.006

Srinuan P, Srinuan C, Bohlin E (2012) Fixed and mobile broadband substitution in Sweden. Telecommunications Policy, Services, regulation and the changing structure of mobile telecommunication markets 36:237-251. doi:10.1016/ j.telpol.2011.12.011

Tranos E (2011) The topology and the emerging urban geographies of the Internet backbone and aviation networks in Europe: a comparative study. Environ Planning A 43:378-392

Tranos E (2013) The Geography of the Internet: Cities, Regions and Internet Infrastructure in. Edward Elgar Publishing, Europe

Tselekounis M, Varoutas D (2013) Investments in next generation access infrastructures under regulatory uncertainty. Telecommunications Policy, Regulating and investment in new communications infrastructure Understanding ICT adoption and market trends: Papers from recent European ITS regional conferences 37:879-892. doi:10.1016/ j.telpol.2013.06.001

Vicente MR, López AJ (2011) Assessing the regional digital divide across the European Union-27. Telecommun Policy 35:220-237. doi:10.1016/j.telpol.2010.12.013

Vinciguerra S, Frenken K, Hoekman J, van Oort F (2011) European infrastructure networks and regional innovation in science-based technologies. Econ Innovation New Technol 20:517-537. doi:10.1080/10438599.2011.562358

Vogelsang I (2010) The relationship between mobile and fixed-line communications: A survey. Information Economics Policy, Wireless Technologies 22:4-17. doi:10.1016/j.infoecopol.2009.12.002

\section{Submit your manuscript to a SpringerOpen ${ }^{\circ}$ journal and benefit from:}

- Convenient online submission

- Rigorous peer review

- Immediate publication on acceptance

- Open access: articles freely available online

- High visibility within the field

- Retaining the copyright to your article

Submit your next manuscript at $\gg$ springeropen.com 